\title{
In-Space Propulsion Technology Products for NASA's Future Science and Exploration Missions
}

\author{
David J. Anderson ${ }^{1}$ (216-433-8709, David.J.Anderson@nasa.gov) \\ Eric Pencil1 (216-977-7433, Eric.J.Pencil@nasa.gov) \\ Todd Peterson ${ }^{1}$ (216-433-5350, Todd.T.Peterson@nasa.gov) \\ John Dankanich ${ }^{2}$ (216-433-5356, John.Dankanich@nasa.gov) \\ Michelle M. Munk ${ }^{3}$ (757-864-2314, Michelle.M.Munk@nasa.gov) \\ ${ }^{1}$ NASA Glenn Research Center, 21000 Brookpark Road, Cleveland, OH 44135 \\ ${ }^{2}$ Gray Research Inc., 21000 Brookpark Road, Cleveland, OH 44135 \\ ${ }^{3}$ NASA Langley Research Center, 1 North Dryden Street, Hampton, VA 23681
}

Abstract-Since 2001, the In-Space Propulsion Technology (ISPT) project has been developing and delivering in-space propulsion technologies that will enable or enhance NASA robotic science missions. These in-space propulsion technologies are applicable, and potentially enabling, for future NASA flagship and sample return missions currently being considered, as well as having broad applicability to future competed mission solicitations. The high-temperature Advanced Material Bipropellant Rocket (AMBR) engine providing higher performance for lower cost was completed in 2009. Two other ISPT technologies are nearing completion of their technology development phase: 1) NASA's Evolutionary Xenon Thruster (NEXT) ion propulsion system, a $0.6-7 \mathrm{~kW}$ throttle-able gridded ion system; and 2) Aerocapture technology development with investments in a family of thermal protection system (TPS) materials and structures; guidance, navigation, and control (GN\&C) models of blunt-body rigid aeroshells; aerothermal effect models: and atmospheric models for Earth, Titan, Mars and Venus. This paper provides status of the technology development, applicability, and availability of in-space propulsion technologies that have recently completed their technology development and will be ready for infusion into NASA's Discovery, New Frontiers, Science Mission Directorate (SMD) Flagship, and Exploration technology demonstration missions. ${ }^{12}$

\section{TABLE OF CONTENTS}

1. INTRODUCTION

2. TECHNOLOGY DEVELOPMENT OVERVIEW ..................2

3. AEROCAPTURE ............................................................2

4. Solar EleCtRIC PROPUlSION (SEP) ..........................6

5. Propulsion COMPONENT TECHNOLOGIES ................9

6. AdvanCEd Chemical Propulsion ............................9

7. SYSTEMS/MISSION ANALYSIS........................................10

8. TECHNOLOGY INFUSION.............................................10

9. CONCLUSION AND FUTURE PlanS ...............................11

ACKNOWLEDGMENTS ...............................................12

REFERENCES ...........................................................................12

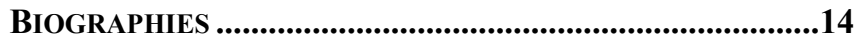

${ }^{1}$ U.S. Government work not protected by U.S. copyright

${ }^{2}$ IEEEAC paper \#1114, Version 4, Updated January 1, 2011

\section{INTRODUCTION}

This paper provides a brief overview of the ISPT project with development status, near-term mission benefits, applicability, and availability of in-space propulsion technologies in the areas of aerocapture, electric propulsion, advanced chemical propulsion, planetary ascent vehicles, Earth return vehicles, other advanced propulsion technologies, and mission/systems analysis tools. These inspace propulsion technologies are applicable, and potentially enabling for future NASA flagship and sample return missions currently under consideration, as well as having broad applicability to future Discovery and New Frontiers mission solicitations.

NASA's Science Mission Directorate (SMD) missions seek to answer important science questions about our planet, the Solar System and beyond. To meet NASA's future mission needs, the goal of the ISPT project is the development of new enabling propulsion technologies that cannot be reasonably achieved within the cost or schedule constraints of mission development timelines, specifically achieving technology readiness level (TRL) 6 prior to preliminary design review (PDR). Since the ISPT goal is to develop products that realize near-term and mid-term benefits, ISPT primarily focuses on technologies in the mid TRL range (TRL 3-6+ range) that have a reasonable chance of reaching maturity in 4-6 years provided adequate development resources. The project strongly emphasizes developing propulsion products for NASA flight missions.

Since 2001, the In-Space Propulsion Technology (ISPT) project has been developing and delivering in-space propulsion technologies that will enable and/or benefit near and mid-term NASA robotic science missions by significantly reducing cost, mass, and/or travel times. ISPT technologies will help deliver spacecraft to SMD's destinations of interest. In late 2006, the ISPT project office was transferred to the Glenn Research Center (GRC) where it manages the ISPT project for the Science Mission Directorate. From 2001 to 2006, the ISPT project office was located at Marshall Space Flight Center (MSFC), where it was initiated and managed. 


\section{TECHNOLOGY DEVELOPMENT OVERVIEW}

ISPT emphasizes technology development with mission pull. Initially the ISPT goal was to develop technologies for Flagship missions. This goal led to the priorities of aerocapture (the use of aerodynamic drag for orbit capture) and electric propulsion. In 2006, the Solar System Exploration (SSE) Roadmap [1] identified technology development needs for Solar System exploration, and described transportation technologies as highest priority (new developments are required for all or most roadmap missions). According to the SSE Roadmap, the highest priority propulsion technologies are electric propulsion and aerocapture. The SSE Roadmap specifically states that "Aerocapture technologies could enable two proposed Flagship missions, and solar electric propulsion could be strongly enhancing for most missions. These technologies provide rapid access, or increased mass, to the outer Solar System." [1] Electric propulsion and aerocapture are suited for enabling significant science return for the outer planetary moons under investigation. The ISPT technologies are quantified to allow greater science return with reduced travel times. The ISPT priorities and products are tied closely to the science roadmaps, the SMD's science plan, and the decadal surveys. Excerpts from the science community are discussed in more detail in Ref. [2]

The ISPT project is currently completing the development efforts in four technology areas. These include Advanced Chemical Propulsion, Aerocapture, Electric Propulsion, and Systems/Mission Analysis. It is one of ISPT's objectives that all ISPT products be ultimately manufactured by industry and made equally available to all potential users for missions and proposals.

Aerocapture technology developments result in better models for: 1) guidance, navigation, and control (GN\&C) of blunt body rigid aeroshells, 2) atmosphere models for Earth, Titan, Mars and Venus, and 3) models for aerothermal effects. In addition to enhancing the technology readiness level (TRL) of rigid aeroshells, improvements were made in understanding and applying inflatable aerocapture concepts. Aerocapture technology was a contender for flight validation on NASA's New Millennium ST9 mission.

Electric propulsion (EP) technology development activities are focusing on completing NASA's Evolutionary Xenon Thruster (NEXT) ion propulsion system. The NEXT system was selected under a competitive solicitation for an EP system applicable to a Flagship mission. NEXT is a 0.6-7$\mathrm{kW}$ throttle-able gridded ion system suitable for future Discovery, New Frontiers, and Flagship missions. At a subcomponent level, ISPT is pursuing the development of a lightweight reliable xenon flow control system as well as standardized EP subcomponent designs. The ISPT project continues the development of other electric propulsion products, such as the High-Voltage Hall Accelerator (HIVHAC) thruster. The HIVHAC thruster is designed as a low cost, highly reliable thruster suited for cost-capped NASA Discovery-class missions.

The primary technology development in advanced chemical propulsion is the development of the Advanced Material Bipropellant Rocket (AMBR) engine, which completed its developmental activities in 2009. Advanced chemical propulsion investments include the demonstration of activemixture-ratio-control and lightweight tank technology. The advanced chemical propulsion technologies have an opportunity for rapid-technology infusion with minimal risk and broad mission applicability.

The systems analysis technology area performs numerous mission and system studies to guide technology investments and quantify the return on investment. Recent focus of the systems analysis area is on developing tools to assist technology infusion. Tool development includes the development of low-thrust trajectory tools (LTTT), a suite of computer programs optimized for developing mission trajectories using EP, and an aerocapture quicklook tool.

\section{Aerocapture}

Aerocapture is the process of entering the atmosphere of a target body to practically eliminate the chemical propulsion requirements of orbit capture. Aerocapture is the next step beyond aerobraking, which relies on multiple passes high in the atmosphere using the spacecraft's drag to reduce orbital energy. Aerobraking has been used at Mars on multiple orbiter missions. Aerocapture, illustrated in Figure 1, maximizes the benefit from the atmosphere by capturing into orbit in a single pass. Aerocapture represents a major advance over aerobraking techniques, by flying at a lower altitude where the atmosphere is denser. Keys to successful aerocapture are accurate arrival state knowledge, validated atmospheric models, sufficient vehicle control authority (i.e. lift-to-drag ratio), and robust guidance during the maneuver. A lightweight thermal protection system and structure will maximize the aerocapture mass benefits.

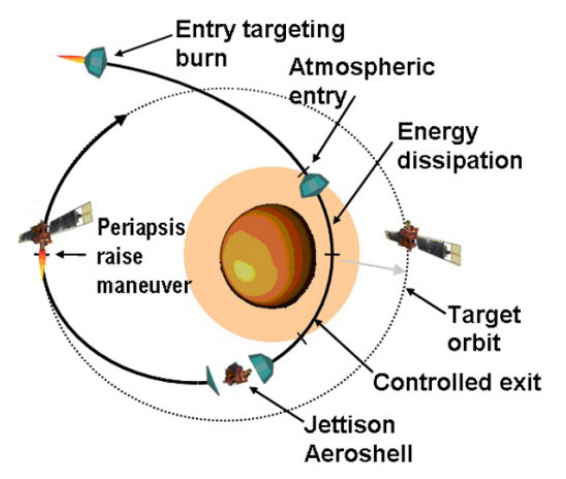

Figure 1 - Illustration of the aerocapture maneuver. 
Executing the aerocapture maneuver itself is what enables the great mass savings over other orbital insertion methods. If the hardware subsystems are not mass efficient, or if performance is so poor that additional propellant is needed to adjust the final orbit, the benefits can be significantly reduced. ISPT efforts in aerocapture subsystem technologies are focused on improving the efficiency and number of suitable alternatives for aeroshell structures and ablative thermal protection systems (TPS). These include development of families of low and medium density (14-36 $\mathrm{lbs} / \mathrm{ft}^{3}$ ) TPS, and the related sensors, development of a carbon-carbon rib-stiffened rigid aeroshell, and high temperature honeycomb structures and adhesives. Development occurred on inflatable decelerators through concept definition and initial design and testing of several inflatable decelerator candidates. Finally, progress has been made through improvement of models for atmospheres, aerothermal effects, and algorithms and testing of a flightlike guidance, navigation and control (GN\&C) system.

Aerocapture enables rapid access to orbital missions at the outer planets and is greatly enhancing or enabling for two of the potential flagship missions in the last Roadmap-Titan Explorer and Neptune-Triton Explorer. For targets in the outer Solar System, aerocapture technology reduces the trip time (by allowing a greater arrival velocity) and delivers a larger payload mass, enabling these missions to be implemented with the current generation of heavy lift launch vehicles. The SSE Roadmap recommends "Aerocapture technologies and flight validation are a high priority to solar system exploration." [1] The March 2008 OPAG meeting minutes recommend that "Aerocapture is a key enabling technology for the outer solar system, particularly at Titan, and some gas giant planets. " [3]

Titan Explorer could be the first to use this technology in a Flagship mission. Because of the deep atmosphere, largescale height, and modest entry velocities, Titan is an attractive target for the use of aerocapture. For a potential Neptune-Triton Explorer (NTE) mission, aerocapture enables the inclusion of two Neptune probes, and transit from Earth to Neptune in less than ten years. Because of the much higher entry velocity and exit velocity near escape, Neptune aerocapture requires a higher-lift vehicle and is a more challenging maneuver than at Titan.

The majority of investments in aerocapture technology occur in advancing the TRL of efficient rigid aeroshell systems. A family of low-density TPS materials carrying the identifier "SRAM" (silicone, reinforced ablative material) was developed under a competitively awarded contract with Applied Research Associates (ARA). These have a density range between $14 \mathrm{lb} / \mathrm{ft}^{3}$ and $24 \mathrm{lb} / \mathrm{ft}^{3}$ with the variable performance achieved by adjusting the ratios of constituent elements. These are applicable for heating rates up to 150 $\mathrm{W} / \mathrm{cm}^{2}$ and $500 \mathrm{~W} / \mathrm{cm}^{2}$ respectively. They could be used on missions with destinations to small bodies such as Titan and Mars. The SRAM family of ablators was tested in both arcjet and solar tower facilities (Figure 2) at the coupon level; one-ft and two-ft square flat panels, and on a onemeter, 70 degree, blunt body aeroshell structure; shown in Figure 3. Another ARA family of low-to-medium density TPS systems (PhenCarb) is phenolic-based, ranges in density between 20 and $36 \mathrm{lb} / \mathrm{ft}^{3}$, and is applicable for heating rates between 200 and $1,500 \mathrm{~W} / \mathrm{cm}^{2}$. In 2011, a solar tower test is planned for a one-meter, 70-degree blunt aeroshell with PhenCarb-28 ablator. Table 1 summarizes the ARA ablative developments and the types of missions for which they are applicable.

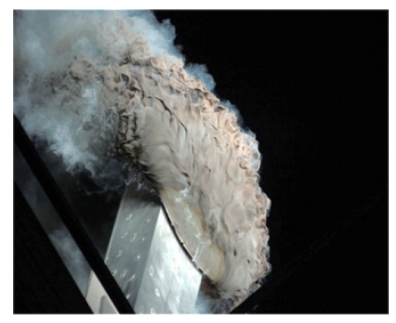

Figure 2 - Solar Tower testing of 1.0-meter aeroshell

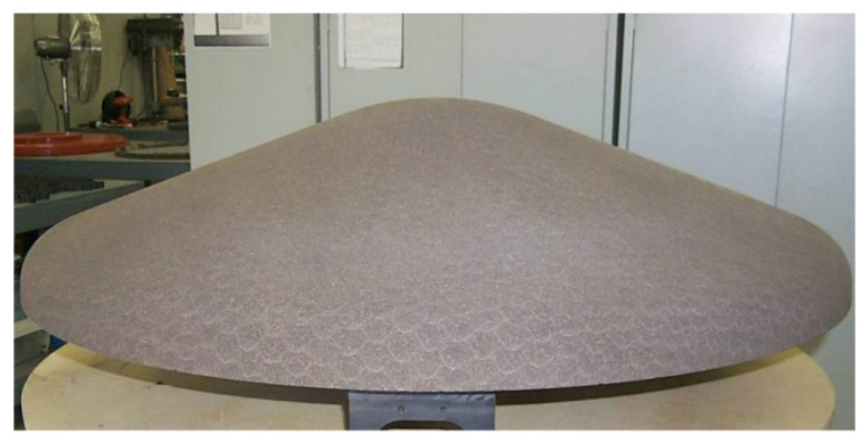

Figure 3 - 1.0-meter Aeroshell with SRAM TPS

Table 1 - Applicable heating ranges and missions for ARA-developed ablators

\begin{tabular}{|c|c|c|}
\hline Ablator & $\begin{array}{l}\text { Heating } \\
\text { Range }\end{array}$ & Application \\
\hline SRAM 14 \& 17 & $\begin{array}{l}\text { 60-200 } \\
\mathrm{W} / \mathrm{cm}^{2}\end{array}$ & Titan, Mars \\
\hline SRAM-20 \& 24 & $\begin{array}{l}140-280 \\
\mathrm{~W} / \mathrm{cm}^{2}\end{array}$ & Mars \\
\hline PhenCarb-20 & $\begin{array}{l}230-795 \\
\mathrm{~W} / \mathrm{cm}^{2}\end{array}$ & Mars, some Earth \\
\hline PhenCarb-28 & $\begin{array}{c}455-1020 \\
W / \mathrm{cm}^{2}\end{array}$ & Venus, Earth \\
\hline PhenCarb-32 \& 36 & $\begin{array}{c}570-1300 \\
W / \mathrm{cm}^{2} \\
\end{array}$ & $\begin{array}{c}\text { Venus, high-speed } \\
\text { Earth, Neptune }\end{array}$ \\
\hline
\end{tabular}

In support of the rigid TPS system, ISPT funded testing of higher temperature adhesives and development of higher temperature composite structures effectively increasing the allowable bond-line temperature from $250^{\circ} \mathrm{C}$ to $325^{\circ}$ or $400^{\circ} \mathrm{C}$ depending on the adhesive and composite construction. This work was performed by ATK, in the 
division formerly known as Composite Optics. Sensors that measure TPS recession with sub-millimeter accuracy were developed at NASA's Ames Research Center and are currently planned for use on the Mars Science Laboratory (MSL) mission. Instrumenting entry systems to gather flight data is of primary importance to understand the environments and resulting vehicle requirements for future missions.

Another advancement, enabled by ISPT funding, is the development of a Carbon-Carbon (C-C) aeroshell that is rib stiffened, reducing the need for an additional structure system. The reduced mass of the structure, coupled with low-density insulation on the inside of the shell, results in a 30 percent mass density improvement over the same size Genesis-like aeroshell. The unsupported system would be applicable for heating rates up to $700 \mathrm{~W} / \mathrm{cm}^{2}$, useful in missions to Mars or for a low-speed Earth return. Higher heat-rate testing indicates the system could be used up to $1200 \mathrm{~W} / \mathrm{cm}^{2}$ with a backup structure, making it applicable to Venus entries and high-speed Earth return missions. The C-C system is relatively non-ablating, possibly offering advantages over more traditional ablative TPS when minimizing ablation products is important. When the $\mathrm{C}-\mathrm{C}$ aeroshell system is mechanically tested to levels that are representative of expected aerocapture loading environments, the system response compares within 10 percent to the finite element model, validating that model for use in predicting system response to other environments. This effort was competitively awarded and completed in early 2007 by Lockheed Martin and their partner CarbonCarbon Advanced Technologies (C-CAT), and resulted in a TRL-6 product applicable for use in multiple NASA science missions.

Ames Research Center (ARC) develops and enhances models that predict the entry thermal environments for aerocapture at Titan, Mars, Venus, and Neptune. In some cases, previous heating estimates are overly conservative because of the lack of resources available to produce validation data or to develop more complicated analysis methods. Coupled models updated with the most current Cassini data reveal, that aerocapture at Titan will load the TPS system at less than $20 \mathrm{~W} / \mathrm{cm}^{2}$ verses prior predictions of 150-300 W/ $\mathrm{cm}^{2}$. [4] Through multiple years of concentrated effort, researchers funded by ISPT made modeling improvements that benefit all future entry missions, and published over 50 papers documenting these results. ISPT also funds the generation or update of engineering level atmospheric models for all primary aerocapture destinations except Earth, and the work is led at the Marshall Space Flight Center (MSFC).

ISPT developed a rigorous, peer-reviewed plan as part of the ST9 New Millennium Proposal to take the SRAM ablative aerocapture system to a TRL 6 by FY09. Though the ST9 flight opportunity was cancelled, ISPT has continued to implement the ground maturation plans preparing the technology for a flight demo or first mission infusion. A 2.65-m diameter high-temperature Aeroshell from ATK, with ARA's SRAM TPS and ARC's instrumentation plugs, is being built as a manufacturing demonstration, to be completed by late 2010 (Figure 4). This unit will have a full manufacturing data package and wil be CT scanned after ablator application, as part of nondestructive evaluation to establish manufacturing quality. An aeroshell of this scale is significant since it it full scale for a Discovery-class mission and more than half scale for a Flagship-class.

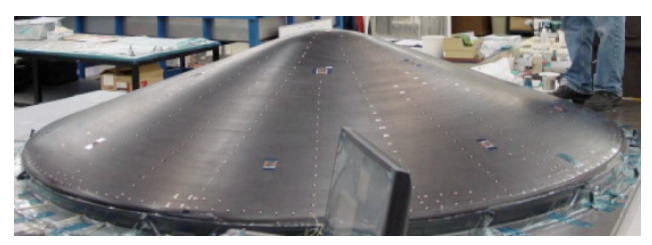

Figure 4 - 2.65-meter high-temperature aeroshell structure being laser scanned for comparison to finite element model

Another effort to raise the TRL for TPS materials includes Space Environmental Effects (SEE) testing. This testing includes radiation exposure, cold soak, and micrometeoroid impact on the ISPT-matured TPS and hot structure materials, to levels representative of a deep space mission. Figure 5 shows the shroud manufactured to cold soak the samples prior to a 7-km/s simulated micrometeoroid impact. Following exposure to these environments, samples will be arcjet tested to aerocapture heat rates and loads, in the Interaction Heating Facility at NASA-Ames. The results will be compared to arcjet tests of unexposed samples. The testing is expected to be complete in mid CY2011.

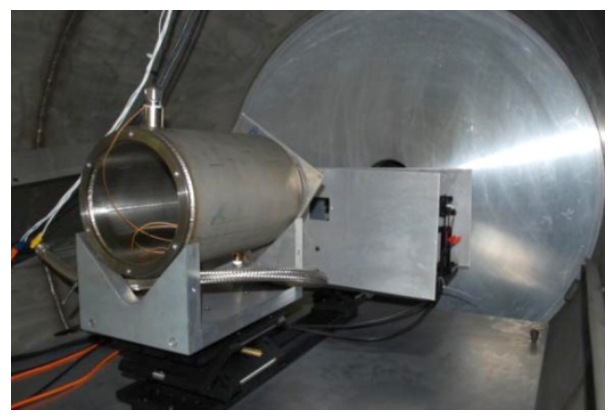

\section{Figure 5 - Cold shroud for micrometeoroid testing (manufactured at NASA-MSFC)}

The aerocapture guidance algorithm used in all ISPT systems analyses, and selected for flight on ST9, is a fully analytic solution of about 300 lines of code, called HYPAS. Ball Aerospace has converted HYPAS to flight software and has completed development of a real-time hardware-in-theloop test bench of a representative GN\&C system for robotic planetary missions (shown in Figure 6). The test bench demonstrates that the guidance performs well even when realistic hardware response times are present. This development [4] brings the TRL of the aerocapture guidance 
to TRL 6, ready for flight infusion. Additional information on aerocapture technology developments can be found in the Discovery program library [5] and in Ref. [6], [7], [8], [9], [10], [11].

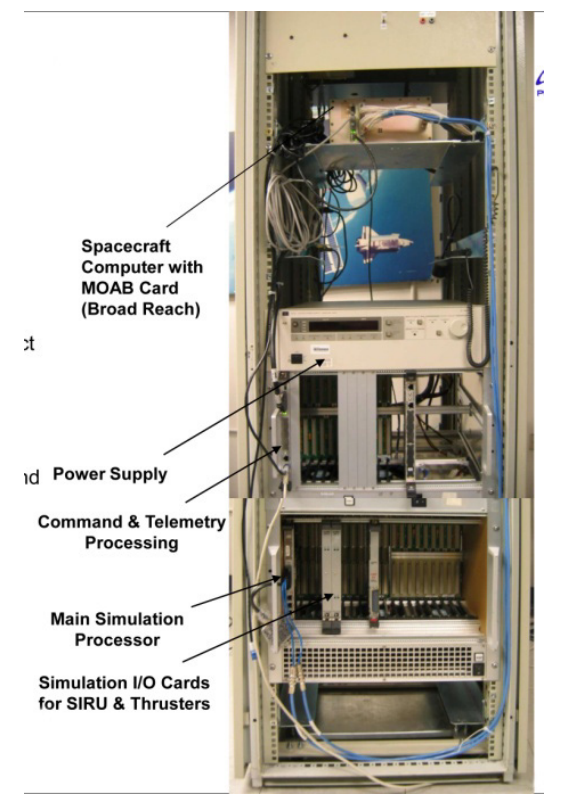

Figure 6 - Test Bench for Aerocapture GN\&C

The use of aerocapture at Titan, Neptune, Venus and Mars has been studied extensively through detailed systems analysis. Mass benefits for all solar system destinations were derived and are documented in Ref. [12]. The largest mass benefit from aerocapture is observed for Neptune, low Jupiter orbits, followed by Titan, Uranus, Venus, and then only marginal gains for Mars (the mass benefit is directly correlated to the amount of velocity change required for each mission). Alternatively, cost benefits are realized for multiple missions. When the overall system mass is reduced, the mission can utilize a smaller launch vehicle, saving tens of millions of dollars. Detailed mission assessment results are in Ref. [13], [14], [15], [16].

The mission mass benefits to Mars are expected to be about 5-15 percent, depending on the scale of the spacecraft. These benefits can be enabling. A multi-center team from Ames Research Center (ARC), Jet Propulsion Laboratory (JPL), Johnson Space Center (JSC), Langley Research Center (LaRC), and MSFC conducted detailed mission and cost analyses for various Mars opportunities. An opposition- class sample return mission that takes less than two years is enabled by aerocapture. Aerocapture enhances conjunctionclass sample-return missions and large Mars orbiters. No new technology gaps are identified that will delay aerocapture implementation on such a mission.

Venus was studied extensively to identify any needs for TPS, guidance, atmospheric or heating models. Detailed analyses evaluated the potential for aerocapture for a Venus Discovery class mission. Aerocapture delivers more than 80 percent additional mass over aerobraking and more than 600 percent over a chemical insertion. [13] Aerocapture reduces Deep Space Network (DSN) time by 121 days. No critical technology gaps are identified for aerocapture at Venus, but investments in TPS are recommended for achieving maximum mass benefits.

Titan continues to be of considerable scientific interest following the success of Cassini/Huygens. Because of its atmospheric structure, it is an ideal candidate for aerocapture. The Outer Planets Flagship (OPF) study considers aerocapture within the baseline mission concept since aerocapture has the capability to deliver more than double the scientific payload of the chemical alternative. Aerocapture may play a key role in accomplishing a reduced Titan mission for a less-than-Flagship budget or providing an alternate Flagship operational scenario.

Aerocapture has proven repeatedly to be an enabling or strongly enhancing technology for several atmospheric targets. The ISPT project team continues to develop aerocapture technologies in preparation for a flight demonstration, and rapid aerocapture analysis tools are being developed and made available to a wider user community. The TPS materials developed through ISPT enhance a wide range of missions by reducing the mass of entry vehicles. The remaining gaps for technology infusion are efficient TPS for Venus and high-speed Earth return, and investments in aerothermal modeling TPS structures and aerodynamics for Neptune. All of the other component subsystems for an aerocapture vehicle are currently at or funded to reach TRL 6 in the next year for the bodies of interest. This assessment of technology readiness is detailed in Ref. [16] and summarized in Figure 7. The structures and TPS subsystems as well as the aerodynamic and aerothermodynamic tools and methods can be applied to small-scale entry missions even if the aerocapture maneuver is not utilized. 


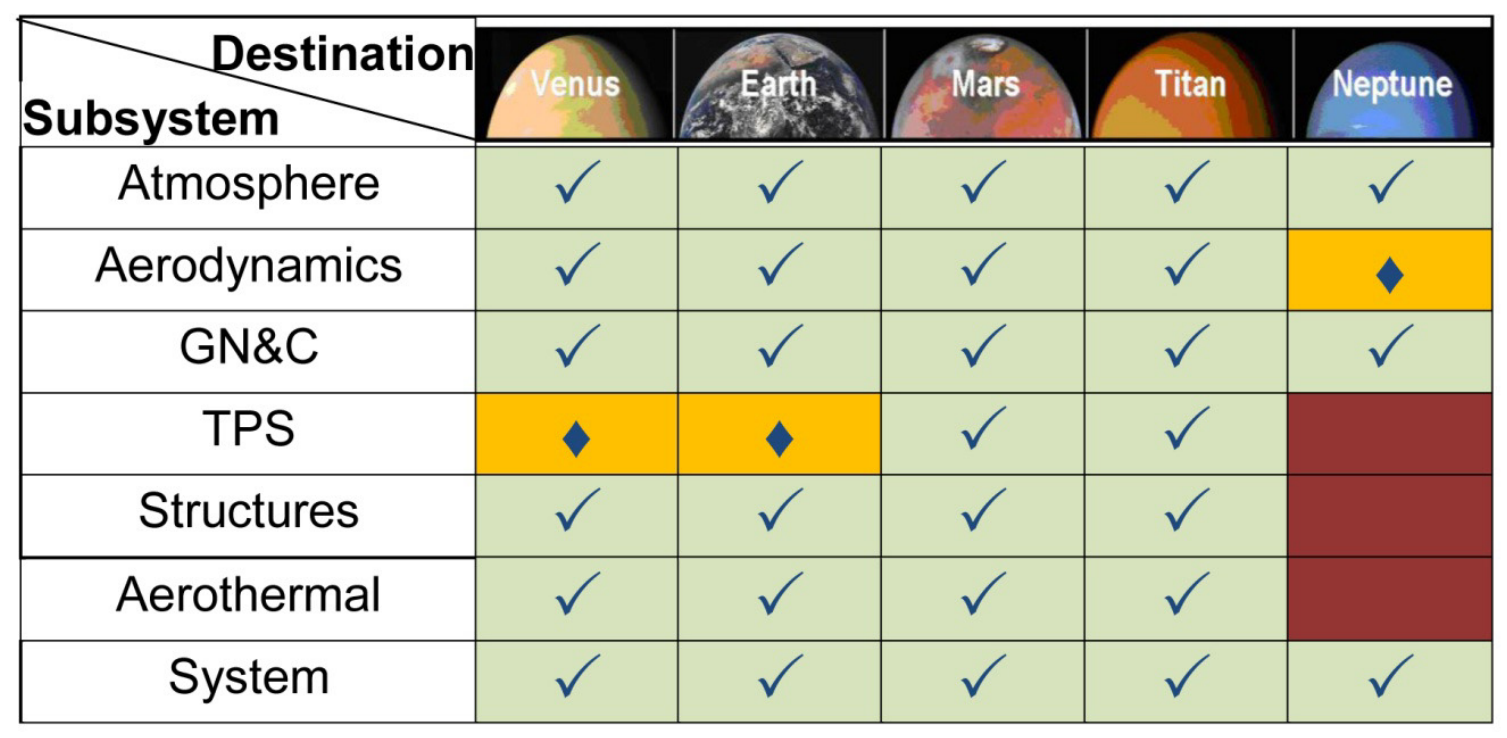

\begin{tabular}{|c|c|c|}
\hline $\begin{array}{c}\text { Ready for } \\
\text { infusion }\end{array}$ & $\begin{array}{c}\text { Some Investment } \\
\text { Needed }\end{array}$ & $\begin{array}{c}\text { Significant Investment } \\
\text { Needed }\end{array}$ \\
\hline
\end{tabular}

Figure 7 - Aerocapture readiness for various targets

Aerocapture cannot reach TRL 6 for the system without space flight validation, since it is impossible to match the flight environment in ground facilities. This validation can be accomplished by utilizing Aerocapture on a science mission, or by a dedicated space flight validation experiment. NASA's Science Mission Directorate has incentivized the use of Aerocapture in its recent Discovery Announcement of Opportunity by increasing the cost cap and assuming some of the risk of using the technology. The outcome of the Discovery selection will not be known for some time. If a Discovery mission utilizing Aerocapture is not selected, aerocapture will likely need to be validated in space before its first mission infusion. A space flight validation is expensive, but the costs will be recouped very quickly if just one mission's launch vehicle cost is reduced as a result of the lower mass requirement enabled by aerocapture. The validation immediately reduces the risk to the first user and validates the maneuver for application to multiple, potentially lower-cost, missions to Titan, Mars, Venus, and Earth. Moreover, once Aerocapture is proven a reliable tool, it is anticipated that entirely new mission possibilities will open up.

\section{Solar Electric Propulsion (SEP)}

Solar Electric Propulsion (SEP) enables missions requiring large in-space velocity changes over time. SEP has applications to rendezvous and sample-return missions to small bodies and fast trajectories towards the outer planets. This is particularly relevant to the Saturn-Titan-Enceladus and the Neptune-Triton missions. In particular, the TitanSaturn System mission demonstrates that improvements to mass, trip-time, and launch flexibility provided by SEP results in significant benefits to the mission.

Significant improvements in the efficiency and performance of SEP are underway. The resulting systems may provide substantial benefits to the SSE Roadmap's planned missions to small bodies and the inner planets.

Electric propulsion is both an enabling and enhancing technology for reaching a wide range of targets. The high specific impulse, or efficiency of electric propulsion system, allows direct trajectories to multiple targets that are chemically infeasible. The technology allows for rendezvous missions in place of fly-bys, and as planned in the Dawn mission can enable multiple destinations.

This technology offers major performance gains, only moderate development risk, and has significant impact on the capabilities of new missions. Current plans include completion of the NASA's Evolutionary Xenon Thruster (NEXT) Ion Propulsion System target at Flagship, New Frontiers and demanding Discovery missions.

The GRC-led NEXT project was competitively selected to develop a nominal $40-\mathrm{cm}$ gridded-ion electric propulsion system. [17], [18] The objectives of this development were to improve upon the state-of-art NASA Solar Electric Propulsion Technology Application Readiness (NSTAR) system flown on Deep Space-1 to enable flagship class missions by achieving: 
- lower specific mass

- $\quad$ higher $\mathrm{I}_{\mathrm{sp}}(4050 \mathrm{~s})$

- greater throughput (current estimates exceed 700 $\mathrm{kg}$ of xenon),

- greater power handling capability $(6.9 \mathrm{~kW})$, thrust $(240 \mathrm{mN})$, and throttle range (12:1).

The ion propulsion system components developed under the NEXT task include the ion thruster, the power-processing unit (PPU), the feed system, and a gimbal mechanism. The NEXT project is developing prototype-model (PM) fidelity thrusters through Aerojet Corporation. In addition to the technical goals, the project has the goal of transitioning thruster-manufacturing capability with predictable yields to an industrial source. To prove out the performance and life of the NEXT thruster, a series of tests have, or are being, performed. The NEXT PM thruster completed a short duration test in which overall ion-engine performance was steady with no indication of performance degradation. A NEXT PM thruster has also passed qualification level environmental testing (Figure 8). As of September 30, 2010 the Long Duration Test (LDT) of the NEXT engineering model (EM) thruster achieved over $525-\mathrm{kg}$ xenon throughput, $1.95 \times 10^{7} \mathrm{~N}$-s of total impulse, and $>31,800$ hours at multiple throttle conditions. The NEXT LDT wear test demonstrates the largest total impulse ever achieved by a gridded-ion thruster. ISPT funding for the thruster life test continues through FY12 with the aim of demonstrating up to $750 \mathrm{~kg}$ of xenon throughput. [19]

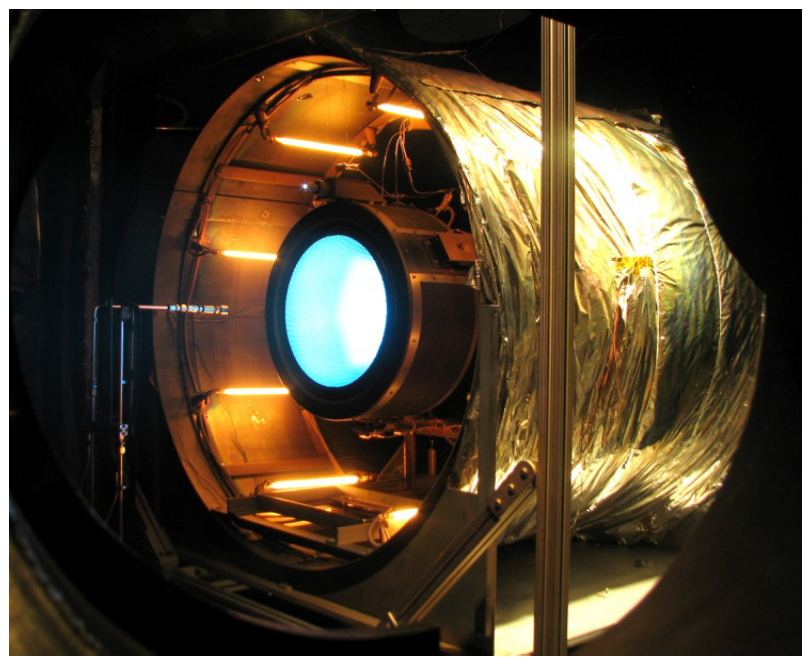

Figure 8 - NEXT thermal vacuum testing at JPL

In addition to the thruster, the system includes a powerprocessing unit (PPU). The PPU contains all the electronics to convert spacecraft power to the voltages and currents necessary to operate the thruster (Figure 9). Six different power supplies are required to start and run the thruster with voltages reaching $1800 \mathrm{VDC}$ and total power processing at $7 \mathrm{~kW}$. L3 Communications designed and fabricated the NEXT Engineering Model (EM) PPU. After completing acceptance tests, the PPU was incorporated into the single- string integrated test. Environmental testing follows including electromagnetic interference/electromagnetic compatibility (EMI/EMC) testing to characterize the capability and emissions of the unit.

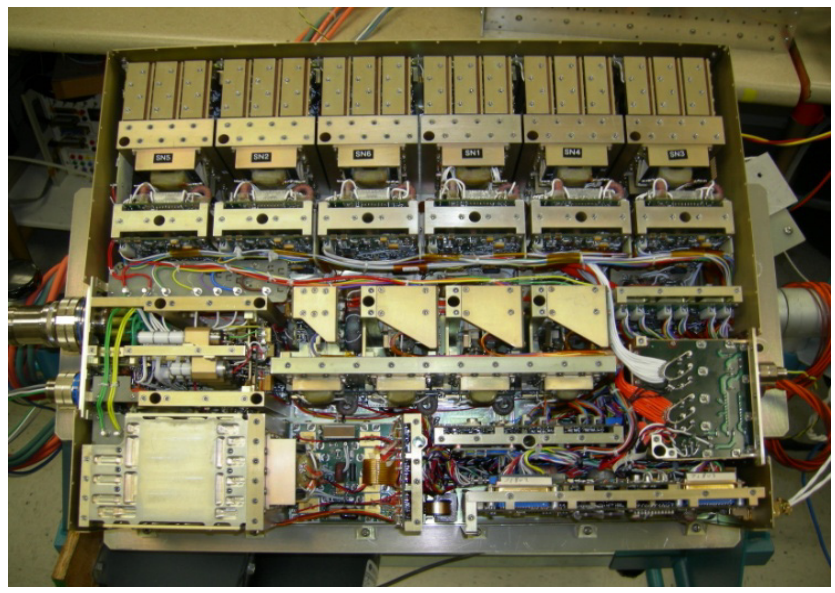

Figure 9 - NEXT Engineering Model PPU

A xenon feed system was developed, and is comprised of a single high-pressure assembly (HPA) with multiple lowpressure assemblies (LPA). The HPA regulates xenon flow from tank pressure to a controlled input pressure to the LPAs. Each LPA provides precise xenon flow control to the thruster main plenum, discharge cathode, or neutralizer cathode. The entire system constitutes the propellant management system (PMS). PMS development is complete and the system passed all performance and environmental objectives. The system is single fault tolerant, 50 percent lighter than the Dawn xenon-feed system, and can regulate xenon flow to the various components to better than three percent accuracy.

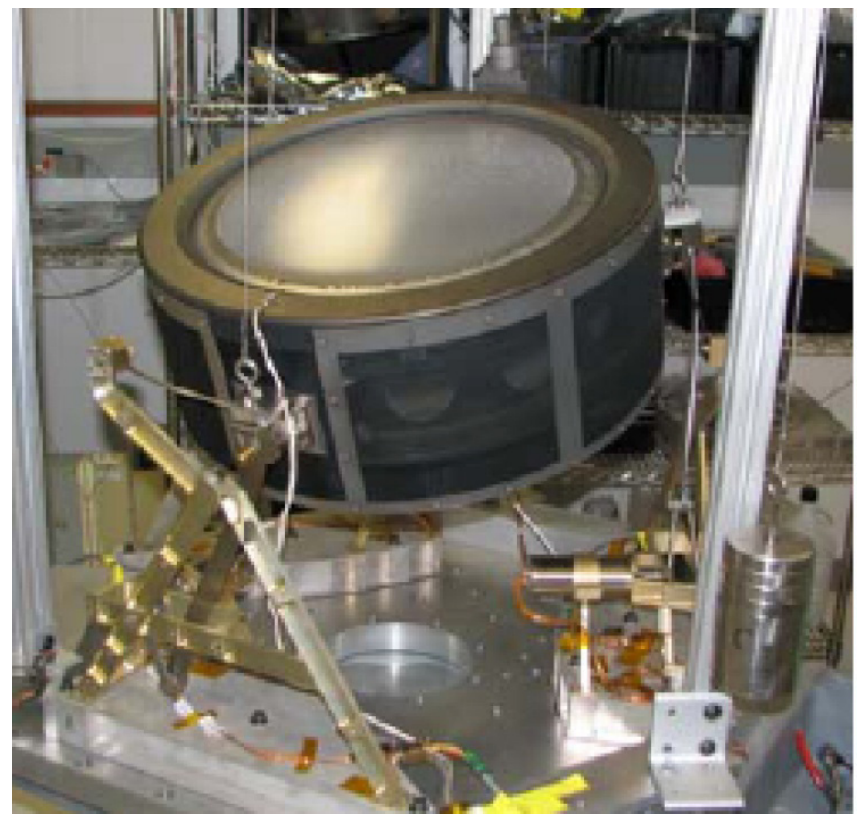

Figure 10 - NEXT Thruster and Gimbal Mechanism 
An engineering-model (EM) fidelity gimbal mechanism was developed that can articulate the thruster approximately 18 degrees in pitch and yaw (Figure 10). The NEXT project team successfully demonstrated performance of the EM gimbal. The gimbal sub-system incorporates a design that improves specific mass over the Dawn gimbal. The gimbal was mated with the thruster, and successfully completed vibration testing first with a mass simulator and then with the NEXT PM thruster.

The project team completed development of the digital control interface unit (DCIU) simulator. This allows communication and control of all system components during testing. A flight DCIU is the interface between the ion propulsion system and the spacecraft. Life models, system level tests, such as a multi-thruster plume interaction test, and various other supporting tests and activities are part of recent NEXT system developments. JPL, Aerojet and L3 Communications are providing major support for the project.

The integrated NEXT system was tested in relevant space conditions as a complete string. With the exception of the PPU environmental tests, this brings the system to a TRL level of 6 and makes it a candidate for all upcoming mission opportunities. The life test demonstrates sufficient throughput for many science destinations of interest. The test plan is to continue into the coming years validating greater total impulse capability with the aim of demonstrating $750 \mathrm{~kg}$ of xenon throughput. Additional information on the NEXT system can be found in the NEXT Ion Propulsion System Information Summary in the New Frontiers and Discovery program libraries. [5], [19], [20]

In the original solicitation, NEXT was selected as an electric propulsion system for flagship missions. NEXT is the most capable electric propulsion system ever developed. A single NEXT thruster:

- uses seven kilowatts of power,

- has an estimated propellant throughput capability of over $750 \mathrm{~kg}$,

- has a lifetime of over 35,000 hours of full power operation,

- $\quad$ has a total impulse capability of approximately 30 million N-s, or about three times that of the SOA DAWN thrusters.

This performance leads to benefits for a wide range of potential mission applications.

The NEXT thruster has clear mission advantages for very challenging missions. For example, the Dawn Discovery Mission only operates one NSTAR thruster at a time, but requires a second thruster for throughput capability. For the same mission, the NEXT thruster could deliver mass, equivalent to doubling the science package, with only a single thruster. Reducing the number of thrusters reduces propulsion system complexity and spacecraft integration challenges. Comparisons between the State-of-the-Art
(SOA) NSTAR thruster and the NEXT thruster are shown below in Table 2.

Table 2 - Performance comparison of NSTAR and NEXT ion thrusters

\begin{tabular}{|ccc|}
\hline Characteristic & $\begin{array}{c}\text { NSTAR } \\
\text { (SOA) }\end{array}$ & NEXT \\
\hline Max. Thruster Power $(\mathrm{kW})$ & 2.3 & 6.9 \\
\hline $\begin{array}{c}\text { Max. Thrust (mN) } \\
\text { Thrust) }\end{array}$ & 91 & 236 \\
\hline $\begin{array}{c}\text { Throttle Range (Max./Min. } \\
\text { Max. Specific Impulse (sec) }\end{array}$ & $\mathbf{3 1 2 0}$ & $\mathbf{4 1 9 0}$ \\
\hline Total Impulse (x10 ${ }^{6}$ N-sec) & $>5$ & $>18$ \\
\hline Propellant Throughput (kg) & 200 & 450 \\
\hline
\end{tabular}

The missions that are improved through the use of the NEXT thruster are those requiring post-launch $\Delta \mathrm{V}$, such as sample returns, highly inclined, or deep-space body rendezvous missions. The comet sample-return mission was studied for several destinations because of its high priority within the New Frontiers mission category. In many cases, chemical propulsion is considered infeasible due to launch vehicle limitations. Specifically for Temple 1 in Ref. [21], [22] the NSTAR thruster is able to complete the mission, but requires large solar arrays and four or five thrusters to deliver the required payload. NEXT would be able to deliver 10 percent more total mass and require half the number of thrusters.

NEXT can not only deliver larger payloads, but also can reduce trip times and increase launch window flexibility. Chemical options exist for several missions of interest. However, the large payload requirements of flagship missions often require multiple gravity assists that both increase trip time and decrease the launch opportunities. In the recent Enceladus flagship mission study, the NEXT SEP option is able to deliver comparable payloads as the chemical alternative using a single Earth gravity assist. The chemical option for Enceladus requires a Venus-VenusEarth-Earth gravity-assist. This adds thermal requirements and increases the trip time by 57 months, from 7.5 to 12.25 years.

The ISPT portfolio of the NEXT system, HIVHAC [23] thruster and subsystem improvements offer electric propulsion solutions for scientific missions previously unattainable. The systems are compatible with spacecraft designs that can inherently provide power for additional science instruments and faster data transfer rates. Scientists can open their options to highly inclined regions of space, sample return or multi-orbiter missions, or even deep-space 
rendezvous missions with more science and reduced trip times.

\section{Propulsion Component TeChNOLOGIES}

NASA's In-Space Propulsion Technology project invested in the Advanced Xenon Feed System (AXFS) for electric propulsion systems. The feed system is designed for an increased reliability combined with a decrease in system mass, volume, and cost as compared to SOA flight systems and comparable TRL 6 technology. The final development module, the pressure control module (PCM), was completed in 2007. The Naval Research Laboratory (NRL) completed functional and environmental testing of the VACCO PCM in September of 2008. Following the environmental testing, the PCM was integrated with the FCMs and an integrated AXFS with controller was delivered to the project. NASA GRC completed hot-fire testing of the AXFS with the HIVHAC Hall thruster successfully demonstrating hot-fire operation using closed-loop control with downstream pressure feedback and with the Hall thruster discharge current. Follow-on testing will determine the viability of the AXFS to perform single-stage, single module, control from high-pressure xenon directly to a thruster.

The AXFS technology is ready for transition into a qualification program. It achieves its objective [24] by demonstrating accurate xenon control with significant system reduction in mass and volume through the use of integrated modules for low-cost control options and/or reliability beyond practical SOA technology implementation. The resultant feed system represents a dramatic improvement over the NSTAR flight-feed system and represents an additional 70 percent reduction in mass, 50 percent reduction in footprint, and 50 percent reduction in cost over the baseline NEXT feed system at TRL 6 . The project successfully completed the integrated system testing and advanced the modules to TRL 6. [25]

In order to reduce costs for NASA science mission and leverage recent feed system flight experiences, JPL has developed a standard architecture for electric propulsion systems. One task under development is the maturation of the Digital Control Interface Unit (DCIU). The brassboard DCIU was designed and fabricated as shown in Figure 11. The unit is undergoing functionality tests with flight software routines and operates with resistive loads. The feed system design approach is valid for either Hall or ionthruster systems and can utilize either commercial or NASA-specific components. Critical components of the simplified feed system were obtained for a demonstration test performed with an NSTAR-like laboratory-ion thruster. A single-string feed system was assembled using flight-like components consisting of a mechanical regulator and the proportional flow control valves, pressure transducers, and flow control devices necessary for a low-pressure assembly. The tests demonstrate operation over a representative throttle table and characterized system operation including flow stability and throttling performance. [26]

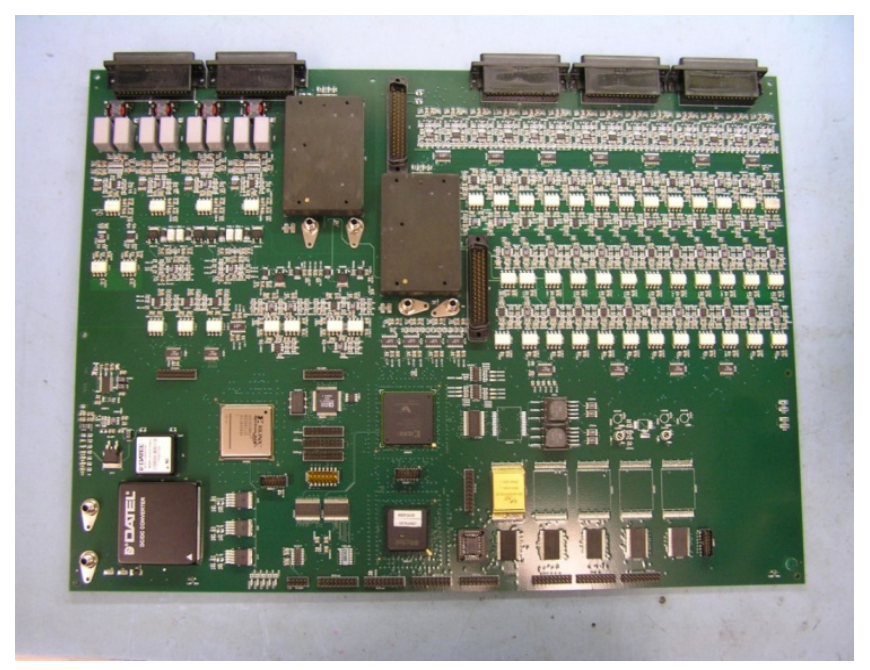

Figure 11 - Standard Architecture Brassboard DCIU.

\section{Advanced Chemical Propulsion}

ISPT's approach to the development of chemical propulsion technologies is primarily the evolution of subcomponent technologies that still offers significant performance improvements. The investments focus on items that would provide performance benefit with minimal risk with respect to the technology being incorporated into future fight systems.

The mission benefits in advanced chemical propulsion are synergistic, and the cumulative effects have tremendous potential. The infusion of the individual subsystems separately provides reduced risk, or combined provides considerable payload mass benefits. Ref [27] has a thorough description of the complete Advanced Chemical Propulsion effort that was concluded in 2009.

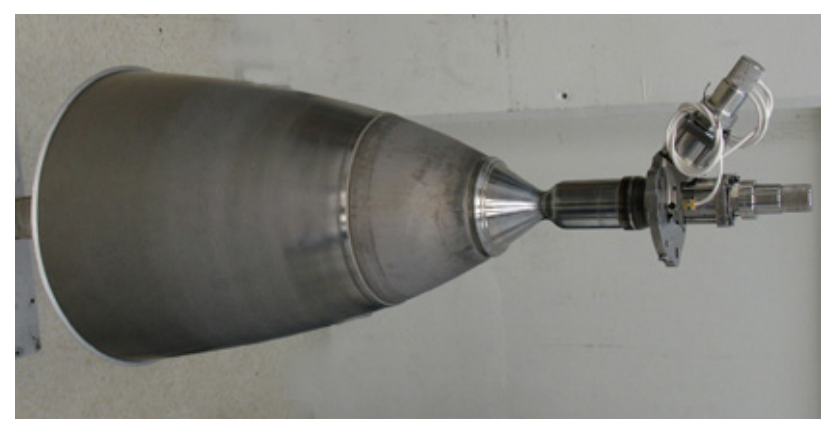

Figure 12 - AMBR engine test article

The single largest investment within the advanced chemical propulsion technology area was the Advanced Materials Bipropellant Rocket (AMBR) engine (Figure 12), which was awarded, through a competitive process, to Aerojet Corporation in FY2006. The AMBR engine is a high temperature thruster that aimed to address cost and manufacturability challenges of using iridium coated rhenium chambers. The project [28] includes the manufacture and hot-fire tests of a prototype engine 
demonstrating increase performance and validating new manufacturing techniques. Performance testing was conducted on the AMBR engine in October 2008 and February 2009 with long duration testing in June 2009. The thruster demonstrated an $\mathrm{I}_{\mathrm{sp}}$ of 333 seconds, which is the highest ever achieved for hydrazine/NTO (nitrogen tetroxide) propellant combination. The project also completed vibration (Figure 13), shock, and long duration testing to raise the TRL to 6 . Additional information is found in the AMBR information summary in the New Frontiers and Discovery program libraries. [5], [20], [29]

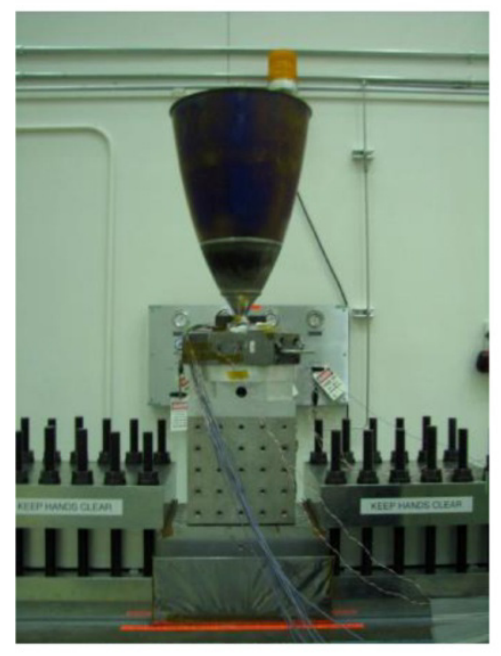

Figure 13 - AMBR shock test in X-direction

\section{SyStems/Mission ANAlysis}

Systems analysis is used during all phases of any propulsion hardware development. The systems analysis area serves two primary functions:

(1) to help define the requirements for new technology development and the figures of merit to prioritize the return on investment,

(2) to develop new tools to easily and accurately determine the mission benefits of new propulsion technologies allowing a more rapid infusion of the propulsion products.

Systems analysis is critical prior to investing in technology development. In today's environment, advanced technology must maintain its relevance through mission pull.

The second focus of the systems analysis project area is the development and maintenance of tools for the mission and systems analyses. Improved and updated tools are critical to clearly understand and quantify mission and system level impacts of advanced propulsion technologies. Having a common set of tools increases confidence in the benefit of ISPT products both for mission planners as well as for potential proposal reviewers. Tool development efforts were completed on the Low-Thrust Trajectory Tool (LTTT) and the Advanced Chemical Propulsion System (ACPS) tool.

Low-thrust trajectory analyses are critical to the infusion of new electric propulsion technology. Low-thrust trajectory analysis is typically more complex than chemical propulsion solutions during the preliminary mission design phase. Some of the heritage tools prove to be extremely valuable, but cannot perform direct optimization and require good initial guesses by the users. This leads to solutions difficult to verify quickly and independently. The ability to calculate the performance benefit of complex electric propulsion missions is intrinsic to the determination of propulsion system requirements. The ISPT office invested in multiple low-thrust trajectory tools that independently verify low thrust trajectories at various degrees of fidelity.

The ISPT low-thrust trajectory tools suite includes Mystic, the Mission Analysis Low Thrust Optimization (MALTO) program, Copernicus, Optimal Trajectories by Implicit Simulation (OTIS) program, and Simulated N-body Analysis Program (SNAP). Mystic is a high fidelity tool capable of N-body analysis and is the primary tool used for trajectory design, analysis, and operations of the Dawn mission. MALTO is a medium fidelity tool for trajectory analysis and mission design. Copernicus is suitable for both low and high fidelity analyses as a generalized spacecraft trajectory design and optimization program. OTIS is a high fidelity optimization and simulation tool and SNAP is a high fidelity propagator. While some of the tools are export controlled, the ISPT website does offer publicly available tools and includes instructions to request tools with limited distribution. Initial versions were first formally released in 2006, but all receive continual updates.

ISPT products can ease technology infusion because of the ability for the user community to rapidly and accurately access the mission level impacts. In addition to the tools currently available, the ISPT project also sponsored the development of an Aerocapture quicklook tool to allow users an opportunity to quantify mission benefits of an aerocapture system including mass properties and geometry. Every effort will be made to have these tools validated, verified, and made publicly available. Instructions to obtain the tools currently available are provided on the ISPT project website. [30]

\section{TECHNOLOGY INFUSION}

The ISPT project is developing several technologies that reached TRL 6 and are potentially applicable for infusion into future, Flagship, New Frontiers, and Discovery mission opportunities. Three technologies in particular are the NASA's Evolutionary Xenon Thruster (NEXT) ion propulsion system, the Advanced Material Bi-propellant Rocket (AMBR) engine, and Aerocapture. ISPT and NASA are exploring several different paths to get its technology 
investments infused into future NASA, DOD, or commercial missions.

NASA recognizes that it is desirable to fly new technologies that enable new scientific investigations or to enhance an investigation's science return. The SSE Roadmap states that NASA will strive to maximize the payoff from its technology investments, either by enabling individual missions or by enhancing classes of missions with creative solutions. Discovery, New Frontiers, and Flagship missions potentially provide opportunities to infuse advanced technologies developed by NASA, and advance NASA's technology base and enable a broader set of future missions. To benefit from its technology investments, NASA provided an incentive to encourage the infusion of NEXT ion propulsion system or the AMBR engine into mission proposals in response to the New Frontiers 3 Announcement of Opportunity (AO). NASA is also offering an incentive to encourage the infusion of NEXT ion propulsion system, the AMBR engine, or aerocapture into mission proposals in response to the upcoming Discovery 2010 Announcement of Opportunity (AO). The Discovery 2010 AO was released on June 7, 2010 with proposals due September 2, 2010. Under these AOs, proposers are offered an option of adopting one of the specific technologies for insertion into their missions. NASA would then share in the flight development costs of the proposed advanced technology, up to certain amounts specified in the AO depending upon which technology is proposed.

Beyond the New Frontiers and Discovery opportunities, ISPT continues to seek opportunities to infuse NEXT, AMBR, Aerocapture, and its other technologies into a wide range of possible future mission opportunities. The ISPT project office and NEXT team personnel are actively supporting various flagship science definition team (SDT) studies. See the ISPT Overview paper in the 2010 IEEE Aerospace Conference for more details regarding these studies. [16] ISPT personnel supported several white papers that were developed in response to the current planetary science decadal survey development activities in 2009/2010. ISPT contributes to identifying the technology development that is required to accomplish the future missions being contemplated. Finally, NEXT and Aerocapture are showing up several times in Exploration Systems Mission Directorate (ESMD) and Office of the Chief Technologist (OCT) planning activities in 2010.

\section{Conclusion and Future Plans}

Known future missions of interest for NASA and the science community, and those that are yet to be conceived, continue to demand propulsion systems with increasing performance and lower cost. This paper explained how the ISPT project has been developing propulsion technologies for NASA missions to address this demand. ISPT will complete current developments to TRL 6 in the next year, and in the future will continue to support mission infusion. Among these is the NEXT electric propulsion system, which wraps-up PPU development and testing in 2011, but continues long-duration life testing for several more years. The NEXT system is available for all future mission opportunities. The AMBR engine reached TRL 6 with the completed development of the high temperature bipropellant chemical thruster in 2009, and wrapped-up the final reporting and documentation in early 2010. Finally, an aerocapture system comprised of a blunt body TPS system, the GN\&C, sensors and the supporting models achieved its technology readiness in mid 2010. Beyond completing the currently funded NEXT and Aerocapture activities, future work for NEXT, AMBR, and Aerocapture will most likely be in response to being included on a selected Discovery AO proposal or other NASA technology infusion opportunity. Regardless, if the mission requires electric propulsion, aerocapture, or a conventional chemical system, ISPT technology has the potential to provide significant mission benefits including reduced cost, risk, and trip times, while increasing the overall science capability and mission performance. Aerocapture and electric propulsion are frequently identified as enabling or enhancing technologies.

The forthcoming release of the planetary science decadal survey in March 2011 will identify technology needs/gaps for future science missions of interest. Once the survey has been released, ISPT will work with the Planetary Science Division (PSD) to identify what propulsion technologies will be pursued in the future. It is anticipated that the planetary decadal survey will identify the need for future work in electric and chemical propulsion, and aerocapture. So, new work in electric propulsion, chemical propulsion, and Aerocapture will be responsive to the missions and technology needs identified in the planetary science decadal survey. Until that point, ISPT will continue to look for ways to reduce system level costs and enhance the infusion process.

The cost of life testing of electric propulsion thrusters is one area where the savings are expected to be significant. Standardizing on common components or sub systems and utilizing modular stages for multiple missions is a way to reduce propulsion system costs. Performance enhancements tasks are anticipated in the area of electric propulsion through design and material improvements to achieve longer thruster life. Costs are addressed in the design process of the Hall thruster, and through modular design and shared hardware for NEXT and other electric propulsion systems. In the aerocapture area, the development plan for the rigid body aeroshell technologies follows a development plan proposed to the New Millennium ST9 mission. In the chemical and component area, development in materials and engine designs continues to improve performance and reduce costs through advanced manufacturing techniques.

Current EP systems are designed for widely varying input power levels to account for the spacecraft's motion around the solar system. Future propulsion needs may include an electric propulsion system that is powered by a radioisotope-powered generator. If the vehicle does not need 
to rely on solar power, then the propulsion system is simpler and lighter. The system can be optimized around a known constant input power.

\section{ACKNOWLEDGMENTS}

The results and findings presented here are based on work funded by the National Aeronautics and Space Administration (NASA), Science Mission Directorate (SMD). ISPT implements the project through task agreements with NASA centers, contracts with industry, and via grants with academic institutions. Implementing NASA centers include Ames Research Center (ARC), Glenn Research Center (GRC), Jet Propulsion Laboratory (JPL), Langley Research Center (LaRC), and the Marshall Space Flight Center (MSFC). There are also numerous industry partners in the development of the ISPT products. The authors acknowledge the technical achievements by the respective NASA and contractor teams and the contributions of the respective technology area project managers. In addition, many thanks to Linda Nero for her administrative, editorial, and clerical support of this paper.

\section{REFERENCES}

[1] "2006 Solar System Exploration Roadmap for NASA's Science Mission Directorate," September 2006.

[2] Anderson, D. J. et. al., "The NASA In-Space Propulsion Technology Project, Products, and Mission Applicability," 2009 IEEE Aerospace conference, March 2009, Paper \#1176.

[3] "March 2008 OPAG Meeting Report," Cited May 27, 2008, http://www.lpi.usra.edu/opag/

[4] Masciarelli, J., et al, "Demonstration of an Aerocapture GN\&C System Through Hardware-in-the-Loop simulations," AAS 10-032, AAS Guidance and Control Conference, Breckenridge, CO, February, 2010.

[5] Discovery Program Library Web site http://discovery.larc.nasa.gov/dpl.html

[6] Congdon, W. M., "Family Systems of Advanced Charring Ablators for Planetary Aerocapture and Entry Missions," 1st NSTC, University of Maryland, June 19-21, 2007.

[7] Wright, M. J., Bose, D., and Olejniczak, J., "The Effect of Flowfield-Radiation Coupling on Aeroheating for Titan Aerocapture", AIAA Paper No. 2004-0484, presented at the 42nd AIAA Aerospace Sciences Conference and Exhibit, Reno, Nevada, Jan. 2004.

[8] Wright, M. J., Bose, D., and Chen, Y. K., "Probabilistic Modeling of Aerothermal and Thermal Protection Material Response Uncertainties," 53rd JANNAF Joint Propulsion Meeting, Dec. 2005.

[9] Willcockson, W. W., NASA Contractor Report (pending), "Final Summary Report: Aerocapture Aeroshell Technologies (AAT) Program,” January 31, 2007.

[10] Miller, K. L. et al., NASA Contractor Report (pending), "Ultralight-weight Ballute Technology for Aerocapture and Aeroassist Missions," January 2007.

[11] Reza, S., NASA Contractor Report (pending), "Aerocapture Inflatable Decelerator: Lockheed Martin Inflatable Aeroshell Final Report,” January 11, 2007.

[12] Hall, J. L., Noca, M. A., and Bailey, R. W., “Cost-Benefit Analysis of the Aerocapture Mission Set", Journal of Spacecraft and Rockets, Vol. 42, No. 2, pp 309-320. 
[13] Lockwood, M. K., et al., "Systems Analysis for a Venus Aerocapture Mission," NASA TM 2006-214291, March 2006.

[14] Lockwood, M. K., et al., "Aerocapture Systems Analysis for a Neptune Mission," NASA TM 2006-214300, April 2006.

[15] Wright, H. S., et al., "Mars Aerocapture Systems Study," NASA TM 2006-214522, August 2006.

[16] Anderson, D. J. et. al., "The NASA In-Space Propulsion Technology Project's Current Products, and Future Directions," 2010 IEEE Aerospace conference, March 2010, Paper \#1078

[17] Patterson, M. and Benson, S., "NEXT Ion Propulsion System Development Status and Performance", AIAA2007-5199, 43rd AIAA/ASME/SAE/ASEE Joint Propulsion Conference and Exhibit, Cincinnati, OH, July 2007

[18] Benson, S., Patterson, M., et al., "NASA's Evolutionary Xenon Thruster (NEXT) Ion Propulsion Technology Development Status in 2009", IEPC-2009-150, 31st International Electric Propulsion Conference, Ann Arbor, MI, September 2009.

[19] "NASA's Evolutionary Xenon Thruster (NEXT) Ion Propulsion system Information Summary August 2008," New Frontiers Program Library Web site http://newfrontiers.larc.nasa.gov/NFPL.html

[20] New Frontiers Program Library Web site http://newfrontiers.larc.nasa.gov/NFPL.html

[21] Oh, D., Benson, S., Witzberger, K., and Cupples, M., "Deep Space Mission Applications for NEXT: NASA's Evolutionary Xenon Thruster," AIAA-2004-3806, 40th AIAA/ASME/SAE/ASEE Joint Propulsion Conference and Exhibit, Fort Lauderdale, GL, July, 2004.

[22] Cupples, M., Coverstone, V., and Woo, B., “Applications of Solar Electric Propulsion to a Comet Surface Sample Return Mission," AIAA-2004-3804, 40th AIAA/ASME/SAE/ASEE Joint Propulsion Conference and Exhibit, Fort Lauderdale, GL, July, 2004.

[23] Anderson, D. J. et. al., "Sample Return Propulsion Technology Development under NASA's ISPT Project," 2011 IEEE Aerospace conference, March 2011, Paper \#1115

[24] Dankanich, J. W., Cardin, J., Dien, A., Kamhawi, H., Netwall, C. J., and Osborn, M., "Advanced Xenon Feed System (AXFS) Development and Hot-fire Testing," 45th AIAA/ASME/SAE/ASEE Joint Propulsion Conference, Denver, CO, August 2-5, 2009.
[25] Kelley, A. R., and England, J. D., "Precision Flow Metering of Pulsed and Stead State Rocket Engines," JANNAF JPM/MSS/LPS/SPS Meeting, Colorado Springs, CO, May 3-7, 2010.

[26] Snyder, J.S., Randolph, T.M., Hofer, R.R., and Goebel, D.M., "Simplified Ion Thruster Xenon Feed System for NASA Science Missions," IEPC 2009-064, 31st International Electric Propulsion Conference, Ann Arbor, MI, Sept. 2009.

[27] Liou, L., Dankanich, J. W., and Alexander, L. L., "NASA In-Space Advanced Chemical Propulsion Development in Recent Years," 2010 IEEE Aerospace Conference, Big Sky, MT, March 6-13 2010.

[28] Henderson, S., Stechman, C., Wierenga, K., Miller, S., Liou, L., Alexander, L., and Dankanich, J. W., "Performance Results for the Advanced Materials Bipropellant Rocket (AMBR) Engine," AIAA 2010-6883, $46^{\text {th }}$ Joint Propulsion Conference, Nashville, TN, July 2528, 2010.

[29] Advanced Material Bi-propellant Rocket (AMBR) Information Summary August 2008," New Frontiers Program Library Web site http://newfrontiers.larc.nasa.gov/NFPL.html

[30] NASA In-Space Propulsion Technology (ISPT) Web site http://spaceflightsystems.grc.nasa.gov/Advanced/Science Project/ISPT/LTTT/. 


\section{BIOGRAPHIES}

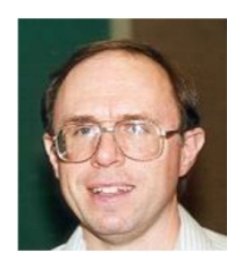

David Anderson is a project manager in the Science Project Office at the NASA Glenn Research Center (GRC). He is currently the Acting Project Manager for the In-Space Propulsion Technology (ISPT) project, and is the SBIR Spacecraft and Platform Subsystems Topic Manager. Formerly, he managed the advanced Radioisotope Power System (RPS) efforts at NASA GRC, was active with new business development and proposal development activities. He also worked in GRC's Systems Management Office, where he was involved in project management oversight activities and led or was involved in several Center and NASA-wide program/project management process improvement teams or activities. He has a B.S. in Aerospace Engineering from the University of Cincinnati and an M.S. in Engineering Management from the Cleveland State University.

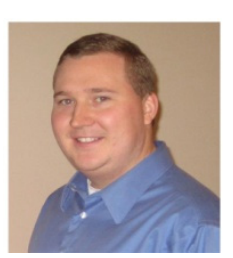

John Dankanich is a Gray Research contractor to the NASA Glenn Research Center. He is the electric propulsion lead systems engineer for the ISPT project. He also serves as a mission and systems analyst for the ISPT project and the Glenn Research Center. John has expertise is in mission and systems analyses, electric propulsion systems, and trajectory optimization. He supported propulsion system development, Mars ascent vehicle design, lunar lander guidance simulations, planetary defense studies, and advanced propulsion design and testing. John has a B.S. in Physics and Aerospace Engineering and an M.S. in Aerospace Engineering from Purdue University.

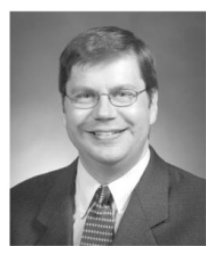

Eric Pencil is Propulsion Projects Area Manager for the In-Space Propulsion Technology Office at NASA Glenn Research Center. He is responsible for the management and execution of the electric propulsion development tasks for NASA Science missions. Previously he worked as a project/research engineer in the electric propulsion research group in which he worked on various electric propulsion technologies at varying stages of maturity from basic research to flight hardware.

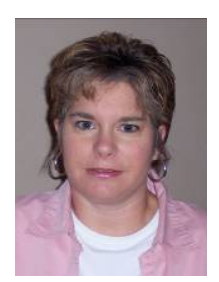

Michelle Munk has been a NASA employee for nearly 20 years, first at the Johnson Space Center, then at the Langley Research Center. She has been involved in Mars advanced mission studies for many years, both robotic and human, contributing interplanetary trajectory analysis and entry and descent analysis. She managed the delivery of International Space Station hardware, and was on the Mars Odyssey aerobraking operations team. In 2002, Ms. Munk accepted a detail assignment to become the Lead Engineer for Aerocapture Technology Development under In-Space Propulsion at Marshall Space Flight Center. She managed the technical work of ISP Aerocapture for nearly five years before becoming the Project Area Manager and returning to Langley in 2007. Ms. Munk is also involved in the Mars Science Laboratory Entry, Descent and Landing Instrumentation (MEDLI) project and contributes to other NASA projects developing entry system technologies. She has a BSAE from Virginia Tech and completed graduate coursework at the University of Houston.

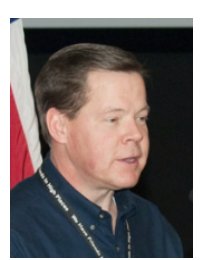

Todd Peterson is a project manager in the Advanced Capabilities Project Office at the NASA Glenn Research Center (GRC). With over 26 years of space flight project experience at NASA GRC, he has extensive propulsion, power and communication system project management experience in human and robotic space flight projects (Space Station, Shuttle/Mir, Deep Space-1, Earth Observer-1, Lunar Reconnaissance Orbiter) and development projects (electric propulsion, chemical propulsion, photovoltaic \& dynamic power systems, microgravity research). He has a B.S. in Mechanical Engineering from the University of Akron and an M.S. in Mechanical Engineering from Cleveland State University. 